Marija S. Đinđić*

Institut za srpski jezik SANU

Srbija

\title{
SEAD GANO ŠLAKOVIĆ, RJEČNIK OSMANSKE LEKSIKE BARSKOGA KRAJA, CETINJE: FAKULTET ZA CRNOGORSKI JEZIK I KNJIŽEVNOST, 2019, 183 STR.
}

\author{
Prikaz \\ UDC 811.163.4'373.45(497.16 Bar)(049.3) \\ https://doi.org/10.18485/kkonline.2021.12.12.14
}

U Rječniku osmanske leksike barskoga kraja prikazan je leksički fond turskog govora Starog Bara u Crnoj Gori. Ovaj govor pripada turskom zapadnobalkanskom dijalekatskom području. Rečnik predstavlja dopunjenu i prerađenu verziju rečnika istoga naslova iz 2013. godine. Autor rečnika Sead Gano Šlaković godinama je prikupljao građu i isključivo iz ljubavi prema svom maternjem dijalektu odlučio je da se upusti u ovaj leksikografski poduhvat.

Dijalekatskom rečniku bi trebalo da prethodi lingvistički opis govora kako bi se znalo koje gramatičke podatke treba uneti u rečnik. $U$ tom smislu, autoru je zadatak pisanja rečnika bio otežan, jer mu nije bio dostupan opis barskog turskog govora. Osim u radu u kojem su date glavne crte govora Staroga Bara, graničnog predela turskog zapadnobalkanskog govornog područja u Crnoj Gori u Jugoslaviji, objavljenom 1970. godine na nemačkom jeziku, autora poznatog dijalektologa Đ. Nemeta (Gy. Németh), sve do izlaska prvog izdanja Šlakovićevog rečnika 2013. godine barski turski govor nije bio predmet naučnog interesovanja. Naime, $Đ$. Nemet je 1956. godine dao osam najznačajnijih crta zapadnobalkanskih dijalekata. Kako naknadno saznaje za postojanje turskog barskog govora, odlaskom u Bar konstatuje da i barski govor poseduje glavne crte zapadnobalkanskih dijalekata. Prema Nemetovom pisanju, još sedamdesetih godina prošloga veka ovaj govor nije se aktivno koristio, a zbog geografske izolovanosti govor karakteriše odsustvo uticaja drugih turskih dijalekata i uočljiv uticaj srpsko-hrvatskog i albanskog jezika.

Bar osvajaju Osmanlije 1571. godine, kada i ulazi u sastav Skadarskoga sandžakata. Bar je bio pod osmanlijskom vlašću tri veka, tokom kojih je dobio izgled orijentalnog grada. Autor navodi da se skoro sva leksika koju je obradio odnosi na

\footnotetext{
*Institut za srpski jezik SANU, Knez Mihailova 36/I, 11000 Beograd, Srbija; e-mail: Marija.Djindjic@isj.sanu.ac.rs
} 
Stari Bar, odnosno tvrđavu i okolna naselja, a nazivi Bar i Stari Bar vezuju se za početak 20. veka, kada započinje gradnja naselja pored mora. Nakon što su Crnogorci oslobodili Bar od turske vlasti 1878. godine, tursko stanovništvo se masovno iselilo u Tursku, dok je jedan deo potomaka turskih porodica nastavio da živi u Baru. Uprkos neizbežnom procesu asimilacije, sačuvan je turski barski govor, koji je predstavljao ne samo sredstvo komunikacije već ujedno i pitanje identiteta i spone sa maticom.

Barski turski govor ostao je poput jednog malog jezičkog ostrva na periferiji zapadnobalkanskog dijalekatskog područja, odnosno severozapadnobalkanske grupe, u koju spadaju turski govori Kosova i govor Bara. Danas su samo starije osobe između 65 i 85 godina sa slabijom govornom kompetencijom turskog govora, dok ga već njihova deca ne govore, nego su im poznate samo izvesne reči i izrazi. U Baru su danas ostale još samo četiri porodice za koje se sigurno zna da imaju tursko poreklo i koje su uspele da odole neizbežnom procesu asimilacije. Prema popisu stanovništva iz 2011. godine, trideset članova ovih porodica se izjasnilo Turcima.

Sead Šlaković, ekonomista po struci, po majci potiče iz porodice Karađuzović, koja je turskog porekla. On je kao dete sve do kraja gimnazije govorio kod kuće sa majkom turski. Rođen je 1944. godine u mahali Brbot, koja se nalazi severozapadno od tvrđave, a u kojoj u tradicionalnom međusobnom poštovanju žive meštani sve tri konfesije. Njegov deda bio je Murteza Karađuzović (1865-1941), muftija crnogorskih Muslimana (1912-1922), koji je u želji da unapredi versku nastavu preveo sa turskog Ilmihal, udžbenik za osnovna znanja iz islamske veronauke, štampan 1900. godine u Carigradu.

Autor u uvodnom delu (str. 7-24) pruža podatke o istorijatu Bara, kao i osnovne fonološke, morfološke, sintaksičke i leksičke karakteristike barskog turskog govora. U novom izdanju rečnika proširen je broj odrednica rečima iz osmanskoga jezika, kao i broj izraza. Takođe, proširena je i analiza karakteristika barskoga turskoga govora. U ovom izdanju navođenje reči uglavnom je prilagođeno turskom dijalekatskom sistemu transkripcije.

Rečnik sadrži 3200 reči i 187 izreka, popisanih i semantički obrađenih na način kako su ostale autoru u pamćenju, a uz korišćenje dostupne literature. Odrednice su navođene akcentovane u skladu sa barskim turskim govorom. Gde je bilo potrebno, u zagradi je navođen oblik iz savremenog turskog jezika, a potom sledi prevodni ekvivalent. Rečnikom nisu obuhvaćeni naučni i tehnološki termini 20. veka, kao ni muslimanska muška i ženska lična imena. Često se uz odrednice u dijalekatskim rečnicima navode primeri upotrebe određene reči, čime njen opis biva potkrepljen, a 
samim tim i pouzdaniji. S obzirom na gotovo neaktivni status barskoga turskog govora, autor nije bio u mogućnosti da potkrepi rečničke odrednice primerima, koji bi bili deo opšte informacije o odrednici i kojima bi se ilustrovala njena upotreba, a definicije učinile na taj način pouzdanijima.

Rečnik (st. 27-171) beleži uglavnom reči koje pripadaju osnovnom leksičkom fondu, reči kojima se imenuju čovek, ljudske osobine, nosioci tih osobina, ljudske radnje, kuća, pokućstvo, jelo, piće, rodbinski nazivi i sl., na primer: insan - insan, čovjek, osoba; erćeklìk (erkeklik) - muškost, odvažnost; darginnlìk (dargınlık) ljutnja, gnjev; hašarılìk (hașarılık) - hašariluk, nestašluk; šàroš (sarhoş) - pijan, napit; pijanica, bekrija; muanät (mu(h)annat) - ośetljiv čovjek, težak, cjepidlaka; magbûl (makbûl) - cijenjen, drag, uvažen; bašibòš (bașıboș) praznoglav, tikvan; jezît (yezit) - okrutan, žestok čovjek; tiranin; ićrâm etmà (ikram etmek) - ugostiti (svečano), počastiti; jasäk etmà (yasak etmek) zabraniti; kuläk vermà (kulak vermek) - oslušnuti,poslušati; patırtĩ etmä (patırtı etmek) - larmati; mušäbāk, mušebaik (muşabak) - drvena rešetka na prozorima starinskih kuća; jaläk (yalak) - kućni kameni sudoper; imâm bajıldi (imam bayıldI) - vrsta jela imam bajildi; mualebĩ (muhallebi) - muhalebija, slatko jelo (oriz, brašno, mlijeko, šećer); širà (şıra) - šira, sok od zreloga grožđa prije previranja; đürümdžè (görümce) - zaova, muževljeva sestra; hâla - tetka (očeva sestra); tèze kardašĩ (teze kardeši) - brat od tetke i sl.

U poglavlju Izreke (prema barskom izgovoru) (str. 171-179) zabeležene su brojne višerečne konstrukcije, koje imaju različit status na raznim jezičkim nivoima, različite strukturno-semantičke karakteristike, kao i različito poreklo. Najveći broj njih spada u frazeološko-paremiološke jedinice, dok su u manjem broju zastupljene kolokacije. Prema strukturno-semantičkom kriterijumu, višerečne konstrukcije pripadaju a) frazeološkim jedinicama u užem smislu (frazeologizmi, frazeme): Ćòr muābèt - prazne (bukv. ćorave) priče, razgovor bez veze; Bismilà dema - Reći bismilu; fig. početi posao; Iptèn kazıktàn - S koca i konopca (sastalo se); Bayramdàn Bayramà - Veoma rijetko, od Bajrama do Bajrama; b) frazeološkim jedinicama u širem smislu (pozdravne forme, opraštanja, forme kojima se izražava želja, čuđenje, divljenje, uzrečice, kletve, blagoslovi i sl. formule narodnih govora): Àkšam hàjrolā! - Dobro veče! Srećno veče!; Sabà häjr ōlsùn! - Dobro jutro!; Ajip tìr! - Sramota (je)!; Àla bin berećêt versìn! - Bog vam dao mnogo dobra! Svako dobro!; Čòk jašà - Živio! Nazdravlje! Živio mnogo godina!; Hajırlì ōlsün! - Neka je sa srećom!; Halâl ōlsùn! - Neka je halal (oprošteno)! Prosto bilo!; Harâm ōlsùn! - 
Neka je prokleto!; Sofrà èr zamān dōli ōlsùn! - Sofra vam vazda puna bila! (zahvaljivanje nakon jela); Zijādè olà - Hvala! Imao još više! Više ga bilo!; Käla sālìkle! - Ostani u zdravlju! (Obično su govorile žene pri odlasku); c) izrekama i poslovicama: Agìz vâr dilì jök. - Usta ima, jezika nema. (kompliment za nevjestu); Čôrba čôk, èt jök. - Čorbe puno, mesa nema;. Dostlè ìja ǐča alıšverıš ètma - S prijateljem jedi, pij, (ali) ne trguj!; Esćî dòst dušmàn ōlmàz - Stari prijatelj ne može biti neprijatelj; Ihtijārlık maskaralìk. - Starost je sprdnja; Jamäk buldì kapäk. Nađe lonac poklopac. (Nađe krpa zakrpu); Kari bük, kajîk kućük. - Velika žena, mali čamac. (Govorilo se za nešto nesrazmjerno, neskladno); Ortaklük bataklük! Zajednički posao, loš posao; Zamānlè insân hèršeje alıšì (Zamanla insan her şeye alışır). - Vremenom se čovjek na sve navikne.

Ovaj rečnik će poslužiti i za istraživanja turcizama u crnogorskim govorima i procese pozajmljivanja proisteklih iz dugotrajnog procesa multilingvizma i jezičke interferencije. Na osnovu ovog leksičkog materijala mogle bi se rekonstruisati ili objasniti određene pojave. Na primer, u brojnim crnogorskim govorima (Vasojevići, Prošćenje, Zagarač, Uskoci, Piva) prisutna je leksema pismilet ( prema tur. pis, prljav + millet, narod) u značenju rđava, loša osoba, nitkov, hulja. Jedino je u turskom barskom govoru posvedočen ovaj leksički spoj koji je autor naveo među izrazima: Pìsmillèt! - Pogan! (Kaže se za izuzetno lošeg čovjeka, bezobraznika).

Korpus reči prikupljenih u specifičnom dijalekatskom idiomu pruža polazište ne samo za jezička istraživanja, već i za istraživanja u drugim oblastima, poput etnologije, istorije, narodne duhovne kulture i sl. S druge strane, pitanje dijalekta u Baru će biti i predmet sociolingvističkih istraživanja, odnosno zbog njegovog statusa analiza bi podrazumevala sociolingvističke kategorije poput uzrasta, pola, obrazovanja, multilingvizma, govorne situacije, društvenog konteksta itd. Rečnik je svedok viševekovnog života turskog naroda u Baru, kao i svojevrsna arhiva jezika kojim su oni govorili. Autor je, budući suočen sa odumiranjem svog maternjeg dijalekta, osećao nostalgiju i potrebu da ostavi pisani trag koji bi čuvao identitet i kulturu njegovih govornika i sprečio odumiranje znanja o njima. Na taj način je pružio mogućnost generacijama koje dolaze da premoste prazninu između prošlosti i sadašnjosti koja prati jezik ove male grupe ljudi. Leksika perifernih govora čuva starinu s obzirom na to da se nalaze i razvijaju daleko od matice, što je slučaj i sa turskim barskim govorom. Otvaranjem i prelistavanjem rečnika oživeće glasovi turskih predaka iz mahale Brbot, zvukovi zaboravljenih reči hanuma na popodnevnoj kafi, kao i brojni stari izrazi i priče sa kaldrmisanih barskih sokaka. 